Service social

\title{
Madonna, érotisme et pouvoir, sous la direction de Michel Dion, Paris, Éd. Kimé, 1994, 132 pages.
}

\section{Nicole Boucher}

Volume 45, numéro 1, 1996

Le sexuel et le relationnel

URI : https://id.erudit.org/iderudit/706720ar

DOI : https://doi.org/10.7202/706720ar

Aller au sommaire du numéro

Éditeur(s)

École de service social de l'Université Laval

ISSN

1708-1734 (numérique)

Découvrir la revue

Citer ce compte rendu

Boucher, N. (1996). Compte rendu de [Madonna, érotisme et pouvoir, sous la direction de Michel Dion, Paris, Éd. Kimé, 1994, 132 pages.] Service social, 45(1), 147-150. https://doi.org/10.7202/706720ar d'utilisation que vous pouvez consulter en ligne.

https://apropos.erudit.org/fr/usagers/politique-dutilisation/ 


\section{RECENSIONS}

\section{MADONNA, ÉROTISME ET POUVOIR}

Sous la direction de Michel Dion

Paris, Éd. Kimé, 1994, 132 pages.

Pour tous les intervenants et pour tous ceux qui s'intéressent aux images et aux discours des chercheurs sur les images, ce livre est fortement recommandé. Il concerne, comme le souligne Michel Dion en Introduction, la passion que l'image de Madonna suscite par l'intermédiaire des médias, tant aux États-Unis qu'en France. Les contributions de sociologues américains, français, canadiennes sont regroupées sous deux thèmes: Questions d'identité et Culture rock. En annexe, à la suite de la présentation d'un entretien de Norman Mailer avec Madonna (paru dans Esquire, août 1994), on trouve une information plus factuelle des éléments biographiques de Madonna et une liste de ses productions artistiques. L'ensemble traite avec force du pouvoir symbolique autour du genre, de la race et de la religion construit par Madonna ou donné par les médias sur Madonna. Il amuse souvent par son éloge de la dérision et de l'audace. Madonna, la «bâtarde du vide», celle qui appartient aux générations des blessés qui marchent, la «provocatrice» (p. 129), attire et ils tentent tous de comprendre pourquoi.

Selon Cathy Schwichtenberg, opérant dans un "entre deux», "elle s'expose au monde comme étant "la folle qui met le genre en désordre" » (p. 10). En surexposant le phallus, le garant symbolique de la domination masculine, en dénonçant un «déterminisme » structurel, Madonna se fait, selon elle, «l'ambassadrice la plus enthousiaste» (p. 11) du postmodernisme, du féminisme, de la théorie du «queer» (lutte des homosexuels aux États-Unis) et de la critique radicale de l'ordre et des institutions.

Pour Thomas Nakayama, Madonna, en donnant «de plus en plus de place aux diversités sexuelles et raciales dans son art » (p. 20), 
l'enrichit par son défi à la «sexualité blanche » en tant que modèle culturel standard d'où découle tout pouvoir. Le jeu constant d'images et de mots ambigus autour de la masculinité blanche permettrait de mieux résister aux constructions sociales imposées de notre identité. Selon Madonna, il faut en effet commencer par comprendre son propre érotisme pour être en accord avec soi-même.

Jean Baudrillard s'intéresse aussi au phénomène Madonna car, par la simulation et l'excès, elle renverse les valeurs. Sa stratégie est offensive et elle obtient ainsi une mise en cause de la différence sexuelle en brouillant toutes les cartes. Mais, surtout, il s'interroge sur «le prix à payer» pour l'utilisation comme une arme de l'absence d'identité, d'une «logistique de l'extrême » tournée vers "l'autoréférentialité», la disparition de l'autre et des conflits. Il en conclut que: «La perte d'identité, c'est bien le résultat de cette autonomie radicale que tout le monde veut assumer aujourd'hui [...]. Une fois qu'on est soi-même, on ne sait plus ce qu'on est: ça c'est le paradoxe.» (p. 33). Ne serait-ce que pour cette contribution sur les thèmes de l'autonomie, la différence et l'identité, sur Madonna comme «signal d'alarme», ce livre vaut la peine d'être lu.

Ensuite, Françoise Collen discute de la possibilité d'une subversion commerciale pour conclure que Madonna n'est qu'un «faux prophète du "Gai savoir"» (p. 40). Puis Danielle Charest dénonce le brouillage postmoderne du "paraître » qui maintient les choses en l'état en se substituant aux luttes concrètes contre l'oppression des femmes.

L'article de Nicole-Claude Mathieu, qui n'a «jamais réussi à définir le féminisme» (p. 65), comme celui de Baudrillard, prend très au sérieux le phénomène Madonna et s'interroge "sur l'influence possible d'une métaphore sur la "réalité" » (p. 55). Si postmodernisme et relativisme extrême vont de pair, puisqu'ils ont en commun le psychologisme et l'abandon de l'analyse des rapports sociaux concrets, elle conclut que "ce n'est pas en discourant "à côté" que le postféminisme va sauver la situation » (p. 67) et changer l'organisation très concrète du sexe social dans nos sociétés. C'est aussi une contribution majeure de ce livre par la force de son argumentation sur le thème de l'identité et des pouvoirs inégalitaires économiquement, juridiquement et culturellement institués.

En deuxième partie, le thème de la culture rock est d'abord abordé par Michel Dion qui souligne l'ampleur du traitement par la presse française du phénomène Madonna. En rappelant que Madonna porte son vrai nom, c'est-à-dire celui de Vierge, c'est d'abord et avant tout la transgression religieuse (plus que sexuelle ou raciale) produite par «cet art d'exposition de soi-même, de surexposition» (p. 74) qui l'intéresse. 
En nous démontrant que le problème de leurs propres représentations est central pour les femmes $\mathrm{du} \mathrm{xx}^{\mathrm{e}}$ siècle, qui ont été enfermées dans celles que les hommes et les religions construisent d'elles (Marie, Marie-Madeleine, Ève) mais sans s'y reconnaître, Michel Dion rappelle toute la violence symbolique au fondement des images de la femme contemporaine en Occident et la force du contrôle des sexes mis en oeuvre par l'Église et le star system auquel Madonna reste, malgré tout, fidèle. C'est en analysant minutieusement pourquoi la presse française, choquée par la campagne publicitaire du livre $S e x$, en a finalement assuré le succès que l'on redécouvre toute la force des imaginaires dans l'institution de la société. Merci Michel.

Il enchaîne, après Marie Cipriani-Crauste qui traite brillamment des influences du hard rock sur l'art de Madonna, en étant impressionné "par cette forme d'auto-diffamation qu'elle s'inflige » (p. 95), s'interrogeant sur l'image que la culture rock donne du monde contemporain et sur sa sexualisation intense. La violence, le simulacre et l'imagination sont pour lui « les trois pôles principaux entre lesquels se déploie l'image que donne du monde contemporain la culture rock» (p. 101).

Son analyse de la violence en quelques pages est très instructive et mérite une attention particulière de tous les intervenants ou concepteurs de programmes de lutte contre la violence (conjugale, familiale, des jeunes, etc.). En se distanciant de R. Girard et G. Bataille, Michel Dion considère la violence comme la source «arbitraire» du sacré et de tout pouvoir que l'on se doit de refouler. Or, la violence du rock, en montrant les violences originelles, accomplit un travail de déconstruction, de dénonciation qui «peut aussi se retourner contre soi-même» (p. 102). Une haine sans sujet et sans action possible, sans objet, peut aussi déboucher sur le racisme et le fascisme. Par contre, en revendiquant une civilisation où l'imaginaire de chacun a droit à l'existence et à la reconnaissance, la culture rock est aussi, et peut-être surtout, un appel à «un nouvel art du politique» (p. 104) par la création au quotidien.

Et l'apport de Madonna à la culture rock, à cette déconstruction / reconstruction? En mettant en scène «le jeu de la perte de soi » (p. 110), «qui arrive à tout un chacun » dans un monde en crise partout, elle alimente la volonté rebelle de la culture rock et pousse à l'extrême l'appel explicite à «supprimer les interdits » (p. 115). Réussira-t-elle à atteindre cet objectif? Cela «dépend moins d'elle que du public, et de lui seulement, qui intériorise, réinvente une Madonna imaginaire à partir de ce que Madonna, femme-star, lui donne» (p. 115). Et Madonna, s'y perdra-t-elle elle-même? Cela dépend si elle reste prisonnière, comme Jean Harlow et Marilyn 
Monroe, de l'image publique construite d'elle ou si, plutôt comme Brigitte Bardot et Shirley Temple, elle en sort un jour pour « retrouver un sens à sa vie». Sortir des images toutes faites de nous et du monde, n'est-ce pas notre problème à tous? Puisque Madonna "nous renvoie une image brouillée de notre monde brouillé d'aujourd'hui », «elle est admirée mais pas aimée» (p. 121), surtout des élites. Ni sorcière, ni prophète, elle laisse pourtant toute grande ouverte la poursuite de l'histoire et de la construction du monde en dehors des projets «fantastiques» ou despotiques des dominants.

Inutile de dire que j'ai beaucoup apprécié les analyses du monde contemporain et de la crise que Michel Dion, Jean Baudrillard et Nicole-Claude Mathieu font en utilisant comme prétexte le phénomène médiatique de Madonna. Bien sûr, la construction du monde ne repose pas uniquement sur un imaginaire plus ou moins bien institué et contrôlé, mais, comme Armand Mattelard le démontre ailleurs, la violence symbolique liée à la globalisation et à l'homogénéisation des besoins fait rage plus que jamais en disposant de moyens technologiques, politiques et économiques jusqu'ici inédits. La prudence est donc plus que jamais de mise.

Aucune vision déterministe dans les propos qui sont tenus par les auteurs associés à Michel Dion. Tout simplement un rappel sympathique, sans dogmatisme, du jeu persistant du pouvoir, de la domination, du contrôle symbolique et social, inscrits dans des rapports sociaux profondément inégalitaires. Après la lecture du livre, j'ai commencé moi aussi à m'intéresser au phénomène Madonna comme reflet de la crise, et je me suis beaucoup amusée. Elle ose, peut-être que d'autres le feront aussi, sans dramatiser, simplement se réapproprier sa vie, son quotidien et son imaginaire. Les femmes ne se reconnaîtront sûrement pas dans l'image donnée par Madonna, mais elles y trouveront peut-être l'envie de sortir de toutes ces images contradictoires construites d'elles, en dehors d'elles, pour enfin retrouver un soi en contexte, intelligible pour soi. C'est l'histoire d'une vie, c'est l'histoire du monde où la violence, loin d'être destructrice, "paraît liée à la capacité qu'a l'homme, et lui seul, de se transcender, de penser cette transcendance et, par là, de s'affirmer, de se poser en tant qu'être humain dans la nature et face aux autres» (Michel Dion, p. 102). Encore merci Michel, ceux qui sauront lire puiseront dans Madonna, érotisme et pouvoir toute la richesse de la déconstruction / reconstruction. Bonne lecture.

Nicole BOUCHER

Travailleuse sociale et sociologue Professeure, École de service social

Université Laval 